\title{
IMPROVING THE ACTIVITIES OF THE PROSECUTOR'S OFFICE FOR PREVENTING CRIMES OF EXTREMISM AMONG MINORS ${ }^{1}$
}

\author{
Pavel P. Fantrov \\ Volgograd State University, Volgograd, Russian Federation
}

Mikhail V. Bobovkin

Russian University of Transport, Moscow, Russian Federation; Bauman Moscow State Technical University, Moscow, Russian Federation; Moscow University of the Ministry of Internal Affairs of Russia named after V.Ya. Kikot, Moscow, Russian Federation

\section{Stanislav A. Medentsov \\ Prosecutor's Office of Tsentralny District of Volgograd, Volgograd, Russian Federation}

Introduction: the problem of preventing extremism among minors, which has not lost its current relevance, deserves special attention. It is quite specific; it concerns the prospects of the future generation. Among other tasks that the Prosecutor's Office faces, the prevention of juvenile delinquency, including of extremist orientation, is particularly important. Not only the state and trends of crime of extremism in the future, but also the moral climate in Russian society, largely depend on how this task is solved with the help of the prosecutor's supervision. The purpose of the study: to identify and characterize the priority areas for improving the activities of the Prosecutor's office of the Russian Federation in the context of preventing crimes of extremism among minors. The objectives of the study: to identify and describe the problems of the prosecutor's supervision for the prevention of crimes of extremism among minors; to assess the coordination activities of the law enforcement agencies to combat youth extremism; to develop recommendations for improving the prosecutor's supervision in the field of preventing crimes of extremism among minors. The methodological framework for the study is represented by a system of methods of scientific knowledge, which should include: the general scientific, systemic, institutional and comparative legal ones. Results: the main problems in the activities of the prosecutor's office for the prevention of extremist juvenile delinquency are identified, which the authors of the paper refer to: formalism; the lack of an individual approach to preventive work; the problems of interdepartmental interaction. The authors point out the need to improve the legal regulation of the prosecutor's status as a coordinator and one of the key subjects of the prevention $<$ of offenses of extremism. Conclusions: to increase the efficiency of the prosecutor's supervision in the field of preventing crimes of extremism among minors, it is advisable: to introduce the innovative methods and technologies for influencing juvenile offenders involved in extremist activities (for example, mediation); to improve the mechanism of interaction of all subjects of the system of prevention of juvenile crimes; not formal, but thorough the supervision of the activities of the supervised subjects of prevention and others; to create the specialized units in the structure of the Prosecutor General's Office of the Russian Federation and the Prosecutor's offices of the subjects of the Russian Federation, which could combine all areas of the prosecutor's supervision over compliance with the legislation on juvenile affairs, including countering extremist activities of minors; to improve the level of professional training and qualification of young employees of the prosecutor's office, determining the efficiency of the prosecutor's office, based on the indicators of the real restoration of the rights and freedoms of citizens.

Key words: prosecutor's supervision, prevention of extremism, minors, law enforcement agencies, prosecutor's office, Russian Federation.

Citation. Fantrov P.P., Bobovkin M.V., Medentsov S.A. Improving the Activities of the Prosecutor's Office for Preventing Crimes of Extremism Among Minors. Legal Concept = Pravovaya paradigma, 2021, vol. 20, no. 2, pp. 74-81. (in Russian). DOI: https://doi.org/10.15688/lc.jvolsu.2021.2.10 


\title{
СОВЕРШЕНСТВОВАНИЕ ДЕЯТЕЛЬНОСТИ ПРОКУРАТУРЫ ПО ПРЕДУПРЕЖДЕНИЮ ПРЕСТУПЛЕНИЙ ЭКСТРЕМИСТСКОЙ НАПРАВЛЕННОСТИ СРЕДИ НЕСОВЕРШЕННОЛЕТНИХ ${ }^{1}$
}

\author{
Павел Петрович Фантров \\ Волгоградский государственный университет, г. Волгоград, Российская Федерация
}

\begin{abstract}
Михаил Викторович Бобовкин
Российский университет транспорта, г. Москва, Российская Федерация; Московский государственный технический университет им. Н.Э. Баумана, г. Москва, Российская Федерация; Московский университет МВД России им. В.Я. Кикотя, г. Москва, Российская Федерация
\end{abstract}

\section{Станислав Андреевич Меденцов}

Прокуратура Центрального района г. Волгограда, г. Волгоград, Российская Федерация

\begin{abstract}
Введение: особого внимания заслуживает не потерявшая в настоящее время актуальности проблема профилактики экстремизма среди несовершеннолетних. Она достаточно специфична, касается перспектив будущего поколения. Среди прочих задач, которые стоят перед прокуратурой, особенной является предупреждение преступности несовершеннолетних, в том числе и экстремистской направленности. От того, как эта задача решается с помощью средств прокурорского надзора, во многом зависят не только состояние и тенденции экстремистской преступности в будущем, но и морально-нравственный климат в российском социуме. Цель исследования: выявить и охарактеризовать приоритетные направления совершенствования деятельности системы прокуратуры РФ в контексте предупреждения преступлений экстремистской направленности среди несовершеннолетних. Задачи исследования: выявить и описать проблемы прокурорского надзора по предупреждению преступлений экстремистской направленности среди несовершеннолетних; дать оценку координационной деятельности правоохранительных органов по борьбе с молодежным экстремизмом; разработать рекомендации по совершенствованию прокурорского надзора в области предупреждения преступлений экстремистской направленности среди несовершеннолетних. Методологическая основа данного исследования представлена системой методов научного познания, к которым следует отнести: общенаучные, системный, институциональный и сравнительно-правовой. Результаты: выявлены основные проблемы в деятельности прокуратуры по предупреждению экстремистской преступности несовершеннолетних, к которым авторы статьи относят: формализм; отсутствие индивидуального подхода профилактической работы; проблемы межведомственного взаимодействия. Указана необходимость совершенствования правового регулирования статуса прокурора, как координатора и одного из ключевых субъектов профилактики правонарушений экстремистского толка. Выводы: для повышения эффективности прокурорского надзора в сфере предупреждения преступлений экстремистской направленности среди несовершеннолетних целесообразно: внедрение инновационных методик и технологий воздействия на несовершеннолетних правонарушителей, вовлеченных в экстремистскую деятельность (например, медиативных); совершенствование механизма взаимодействия всех субъектов системы профилактики преступлений несовершеннолетних; не формальный, а тщательный надзор за деятельностью поднадзорных субъектов профилактики и иных; создание специализированных подразделений в структуре Генеральной прокуратуры РФ и прокуратур субъектов РФ, которые могли бы объединить все направления прокурорского надзора за соблюдением законодательства по делам несовершеннолетних, включая и противодействие экстремистской деятельности лиц несовершеннолетнего возраста; повышение уровня профессиональной подготовки и квалификации молодых сотрудников прокуратуры, определение результативности деятельности прокуратуры исходя из показателей реального восстановления прав и свобод граждан.

Ключевые слова: прокурорский надзор, профилактика экстремизма, несовершеннолетние, правоохранительные органы, прокуратура, Российская Федерация.
\end{abstract}

Цитирование. Фантров П. П., Бобовкин М. В., Меденцов С. А. Совершенствование деятельности прокуратуры по предупреждению преступлений экстремистской направленности среди несовершеннолетних // Legal Concept=Правовая парадигма. - 2021. - T. 20, №2. - C. 74-81. - DOI: https://doi.org/10.15688/lc.jvolsu.2021.2.10 


\section{Введение}

Предупреждение экстремистской деятельности несовершеннолетних в современных условиях является одной из приоритетных задач обеспечения общественной безопасности, и важная роль по ее решению отведена прокуратуре. Чтобы эта задача реализовывалась эффективно, необходимо хорошо знать существующие проблемы в этой области, чтобы вырабатывать и применять необходимые средства прокурорского надзора для их разрешения [9, с. 179].

Предупреждение экстремистской деятельности несовершеннолетних осуществляется многими субъектами, то есть она представляет собой многопрофильную систему профилактики. Тем не менее в настоящее время такая система не лишена недостатков. Как справедливо полагает Е.Н. Костенко, «...имеются существенные недостатки в правовой регламентации исследуемой сферы - как в регулировании “профилактической” деятельности органов системы профилактики, являющихся объектами прокурорского надзора исследуемой сферы, так и в актах, организующих прокурорский надзор за исполнением законов о профилактике безнадзорности и правонарушений несовершеннолетних» [4, с. 228]. В этой связи возникает необходимость выявления актуальных проблем прокурорского надзора в контексте предупреждения преступлений экстремистской направленности в молодежной среде, а также разработке рекомендаций по их устранению.

\section{Проблемы прокурорского надзора по предупреждению преступлений экстремистской направленности среди несовершеннолетних}

Проблемы, возникающие в процессе деятельности органов прокуратуры по предупреждению преступлений экстремистского толка среди лиц несовершеннолетнего возраста, взаимосвязаны с проблемами организации системы профилактики правонарушений [8, c. 117]. Среди основных организационных проблем этой системы следует выделить: разобщенность взаимодействия ее субъектов; выполнение правоохранительными органами од- нотипных действий, не влияющих, по большому счету, на конечный результат - предупреждение рецедивных преступлений несовершеннолетних; несовершенство организационноправовых основ ресоциализации лиц несовершеннолетнего возраста; перегруженность сотрудников правоохранительных органов «бумажной» работой, сокращающей непосредственную (контактную) работу с несовершеннолетней молодежью.

В научной литературе можно встретить тезис, что одной из фундаментальных организационных проблем координации деятельности правоохранительных органов по борьбе с молодежным экстремизмом является дезорганизация субъектов системы профилактики преступлений экстремистской направленности. Во многом схожей позиции придерживается и М.Ю. Шамрин, проведя исследование особенностей взаимодействия прокуратуры и уполномоченного по правам ребенка в рассматриваемой сфере. Исследователь выделяет ряд проблем, возникающих при взаимодействии этих правовых институтов, относя к ним следующее: «...отсутствие в российском законодательстве норм, регулирующих реализацию процедуры взаимодействия субъектов системы профилактики; нежелание государственных органов взаимодействовать с омбудсменом; отсутствие у уполномоченных по правам ребенка в субъектах Российской Федерации в отличие от Федерального омбудсмена права рассмотрения жалоб детей на действия территориальных органов исполнительной власти» [7, с. 65-66].

Кроме организационных проблем прокурорского надзора по предупреждению преступлений экстремистской направленности среди несовершеннолетних, можно выделить еще одну не менее значимую - несовершенство регламентации правового статуса прокурора, как координатора и одного из ведущих субъектов профилактики правонарушений экстремистского толка. В частности, А.Ю. Гулягин и А.О. Бозоян справедливо указывают, что разработчикам Федерального закона «Об основах системы профилактики правонарушений в Российской Федерации» от 23.06.2016 № 182-Ф3 следовало бы в нормы этого закона заложить ряд положений, отраженных в Указе Президента РФ от 18.04.1996 № 567 «О координа- 
ции деятельности правоохранительных органов по борьбе с преступностью». Ими отмечается, что в целях обеспечения координации деятельности правоохранительных органов в Федеральном законе «Об основах системы профилактики правонарушений в Российской Федерации» необходимо отразить следующее: «...прокурор наделен полномочиями председателя координационного совещания руководителей правоохранительных органов, таких как истребование необходимой информации, организация рабочих групп из числа работников правоохранительных органов, назначение ответственного секретаря координационного совещания и пр.» [2, с. 56].

При осуществлении надзорных функций Генеральная прокуратура РФ отмечает, что состояние законности в области профилактики безнадзорности и правонарушений несовершеннолетних не соответствует желаемому результату. Анализируя работу органов внутренних дел по предупреждению преступности несовершеннолетних, прокуратура фиксирует недостатки в их деятельности. Анализ этих недостатков важен в исследуемом вопросе с точки зрения планирования и организации работы органов прокуратуры с учетом выявленных недостатков и обстоятельств, которыми они обусловлены. На основании этого, на наш взгляд, целесообразно будет внесение ряда поправок в Федеральный закон «Об основах системы профилактики правонарушений в Российской Федерации», таких как: четко сформулировать цель координационной деятельности по профилактике правонарушений лиц несовершеннолетнего возраста; закрепить алгоритм реализации задач координационной деятельности по профилактике правонарушений, в том числе и экстремистской направленности.

\section{Пути совершенствования} прокурорского надзора

\section{по предупреждению преступлений} экстремистской направленности среди несовершеннолетних

Прокурор наделен широкими полномочиями в сфере предупреждения преступлений экстремистской направленности среди несовершеннолетних. Самым распространенной формой деятельности прокуратуры в изучаемой сфере является осуществление прокурорского надзора, наиболее часто осуществляемого посредством проведения прокурорских проверок. Тем не менее в настоящее время не решены правоприменительные пробелы, касающиеся регламентации порядка применения прокурорами норм права в процессе проведения ими проверок. Так, В.П. Сачков, анализируя процедуру проверки, предлагает усовершенствовать ее, а именно - отдельный, предопределяющий ее ход и результат - планирование. По его мнению, в план проверки необходимо включать следующее: ее объекты и период проведения; вопросы, которые подлежат выяснению; документы, необходимые для истребования; организации либо органы, из которых они будут истребованы [6, c. 320]. На данном отрезке времени примерное содержание плана существует лишь на уровне рекомендации, что приводит к формальному отношению прокуроров к этому этапу своей работы. Для исправления данной ситуации предлагается придание такому плану статуса процессуального документа, с помощью которого при необходимости представится возможным оценить действия прокурора с позиции достаточности принятых им мер по предупреждению экстремистской преступности среди несовершеннолетних.

В целях совершенствования организации прокурорского надзора в рассматриваемой нами сфере необходимо и четкое определение объектов надзора по предупреждению экстремистской преступности среди несовершеннолетних, а также и охарактеризовать его содержание.

Е.Н. Костенко считает объектами надзора субъекты системы профилактики правонарушений среди несовершеннолетних, выделяя 5 групп таких субъектов. К первой относятся комиссии по делам несовершеннолетних и защите их прав; ко второй - организации, осуществляющие образовательную деятельность; к третьей - учреждения для детей-сирот и детей, оставшихся без попечения родителей; к четвертой - специальные учебно-воспитательные учреждения открытого и закрытого типа; к пятой - органы по делам молодежи, наделенные Федеральным законом от 24.06.1999 № 120-Ф3 «Об основах системы профилактики безнадзорности и правона- 
рушений несовершеннолетних» полномочиями по оказанию содействия детским и молодежным общественным объединениям и иным учреждениям и организациям, деятельность которых связана с осуществлением мер по профилактике безнадзорности и правонарушений несовершеннолетних; участию в организации отдыха, досуга и занятости несовершеннолетних. Объектами прокурорского надзора в указанной сфере выступают органы опеки и попечительства, учреждения здравоохранения, органы внутренних дел, а также центры временного содержания несовершеннолетних правонарушителей и учреждения уголовноисполнительной системы [3, с. 31].

Многие исследователи при выявлении проблем предупреждения преступлений экстремистской направленности среди несовершеннолетних указывают на формализм в работе правоохранительных органов. Для решения этой проблемы М.Н. Садовникова совершенно справедливо, на наш взгляд, предлагает активное внедрение медиативных технологий [5, с. 83].

Под медиативными технологиями при работе с лицами несовершеннолетнего возраста, вовлеченными в экстремистскую деятельность, следует понимать использование при работе с этой категорией населения сотрудниками субъектов системы профилактики совокупности инструментов профессиональной медиации, в целях профилактики или разрешения возникающих конфликтов. Их применение позволит привить несовершеннолетним навыки конструктивного взаимодействия для сохранения / восстановления отношений с социальными группами, что, несомненно, является одним из ключевых факторов предупреждения преступлений экстремистской направленности в дальнейшем.

На необходимость применения психологических познаний прокурорами при осуществлении ими работы с несовершеннолетними акцентирует свое внимание Т.Г. Воеводина, приводя пример работы прокурора по поддержанию государственного обвинения в отношении несовершеннолетнего: поскольку психика подростка еще только формируется, то это создает дополнительные возможности для предупредительной работы, поскольку антисоциальные привычки еще не укрепились в сознании ребенка $[1$, с. 76]. В контексте данной проблематики исследователь предлагает внести в Федеральный закон «О прокуратуре Российской Федерации» следующие изменения и дополнения: в ч. 1 ст. 40.1 после слова «профессиональными» добавить слово «психологическими»; дополнить ч. 1 ст. 40.1 новым предложением следующего содержания: «Психологические навыки определяются посредством тестирования». В УПК РФ следует внести следующие изменения: дополнить ч. 5 ст. 246 после слова “исследовании” следующей фразой: “используя психологические навыки”» [1, с. 77].

Так как причины совершения преступления несовершеннолетним всегда связаны с особенностями его личности, прокурору важно выяснять субъективную сторону совершенного деяния. Среди обстоятельств, подлежащих установлению по уголовному делу в отношении несовершеннолетнего, особое значение будут иметь исследование условий его жизни и воспитания, а также уровень его психического развития и иные особенности его личности, согласно п. 2 ч. 1 ст. 421 УПК РФ. В процессе подготовки к судебному разбирательству прокурор особое внимание должен обратить на характеристику личности несовершеннолетнего обвиняемого, его законных представителей, на психологическую атмосферу, в которой находился несовершеннолетний обвиняемый. В ходе судебного разбирательства деятельность прокурора имеет свои психологические особенности - государственному обвинителю необходимо постоянно контролировать ситуацию, уметь ориентироваться при допросах несовершеннолетних подсудимых и других участников судебного процесса, при осуществлении судом иных процессуальных действий, уметь юридически грамотно и корректно не только сформулировать вопрос, но и ответить на вопросы участников судебного разбирательства. Важны сознательный контроль прокурора за собственной речью, умение учитывать реакцию зала при формулировке вопросов. Прокурору важно быть искренним и уметь показать подростку желание не только наказать за содеянное, но и помочь, поддержать его.

Распределение направлений прокурорского надзора за исполнением законов по делам несовершеннолетних по различным струк- 
турным подразделениям органов прокуратуры, без специализации прокурорских работников в рассматриваемой области, может негативно сказаться на продуктивности прокурорского надзора по предупреждению преступлений экстремистской направленности среди лиц несовершеннолетнего возраста. В этой связи, на наш взгляд, целесообразно создание в структуре Генеральной прокуратуры РФ и прокуратур субъектов РФ специализированных подразделений, которые бы объединяли все направления прокурорского надзора за исполнением законодательства в области профилактики и противодействия правонарушений несовершеннолетних, в том числе и экстремистской направленности. Эта необходимость обусловлена, в частности, международными обязательствами Российской Федерации относительно создания системы ювенальной юстиции в стране и специализации сотрудников правоохранительных органов.

\section{Выводы}

Таким образом, все органы прокуратуры осуществляют свои полномочия в соответствии с законодательством, соблюдая предусмотренные законодательством права, свободы и законные интересы физических и юридических лиц. Реализуя конкретные полномочия по противодействию экстремизму среди несовершеннолетних, прокуроры обязаны действовать лишь в пределах своих полномочий, установленных законодательством. Тем не менее не все из направлений деятельности прокуратуры по предупреждению преступлений экстремистской направленности среди несовершеннолетних прямо указаны в федеральных законах. О некоторых из них можно узнать из ведомственных нормативных актов, например, приказов Генерального Прокурора РФ. Кроме того, не все направления деятельности регламентированы исчерпывающим образом. Вероятно, это связано с тем, что при осуществлении правового просвещения выбор направления деятельности по предупреждению преступлений экстремистской направленности среди несовершеннолетних требует творческого подхода. Они не статичны, а динамичны, изменяются с учетом потребностей современного состояния российского социума.
К основным проблемам в деятельности прокуратуры по предупреждению преступлений экстремистского толка несовершеннолетних следует отнести: формализм; отсутствие индивидуального подхода профилактической работы; проблемы межведомственного взаимодействия. Разрешение этих проблем возможно путем внедрения новых методик воздействия на несовершеннолетних правонарушителей, совершенствования механизма взаимодействия всех субъектов профилактики преступлений экстремистской направленности среди несовершеннолетних, специализации прокуроров в деятельности по предупреждению экстремистской преступности несовершеннолетних и иных мер, осуществлять не формальный, а тщательный надзор за деятельностью поднадзорных и иных субъектов профилактики в этой сфере. Кроме того, в целях повышения эффективности прокурорского надзора по предупреждению преступлений экстремистской направленности среди несовершеннолетних необходимо систематически повышать уровень квалификации молодых сотрудников органов прокуратуры, законодательно закрепить полномочия прокурора по императивному приостановлению деятельности организаций экстремистского толка без судебного порядка, с последующей возможностью обжалования его действий в суде.

\section{ПРИМЕЧАНИЕ}

${ }^{1}$ Статья подготовлена при финансовой поддержке гранта РФФИ № 20-011-00688 (А) «Модель профилактики экстремизма в молодежной среде: интеграция деятельности гражданских ассоциаций и силовых структур в контексте правовой социализации».

The reported study was funded by RFBR, project number 20-011-00688 (A) "Model for the prevention of extremism among the youth: integration of the activities of civic associations and law enforcement agencies in the context of legal socialization".

\section{СПИСОК ЛИТЕРАТУРЫ}

1. Воеводина, Т. Г. Применение прокурором психологических знаний при поддержании в суде государственного обвинения по уголовным делам с участием несовершеннолетних / Т. Г. Воеводина 
// Законы России: опыт, анализ, практика. - 2016. № 8. - С. 76-79.

2. Гулягин, А. Ю. Несовершенство правового регулирования статуса прокурора как координатора и субъекта профилактики правонарушений / А. Ю. Гулягин, А. О. Бозоян // Российская юстиция. - 2017. - № 8. - С. 55-58.

3. Костенко, Е. Н. Объекты прокурорского надзора за исполнением законов о профилактике безнадзорности и правонарушений несовершеннолетних / Е. Н. Костенко // Современное право. 2018. -№ 7-8. - С. 28-33.

4. Костенко, Е. Н. Правовое регулирование прокурорского надзора за исполнением законов о профилактике безнадзорности и правонарушений несовершеннолетних / Е. Н. Костенко // Актуальные проблемы российского права. -2018. - № 9. - С. 226-231.

5. Садовникова, М. Н. Востребованность медиативных технологий в системе профилактики преступности несовершеннолетних / М. Н. Садовникова // Сибирский юридический вестник. - 2013. № 2. - С. 82-85.

6. Сачков, В. П. Совершенствование способов защиты прокурором прав и законных интересов несовершеннолетних / В. П. Сачков // Молодой ученый. - 2018. - № 19. - С. 319-321.

7. Шамрин, М. Ю. Взаимодействие Уполномоченного по правам ребенка с органами прокуратуры России: теоретико-правовой аспект / М. Ю. Шамрин // Административное право и процесс. - 2016. - № 12. - С. 60-68.

8. Шинкарук, В. М. Координация деятельности правоохранительных органов и конструктивных ассоциаций граждан в контексте профилактики молодежного экстремизма / В. М. Шинкарук, П. П. Фантров // Вопросы российского и международного права. - 2020. - № 7А. - С. 111-120.

9. Шинкарук, В. М. Противодействие экстремизму в молодежной среде: роль прокурорского надзора за исполнением законодательства в данной сфере / В. М. Шинкарук, П. П. Фантров, Н. А. Соловьева // Вестник Волгоградской академии МВД России. - 2020. - № 4. - С. 178-188.

\section{REFERENCES}

1. Voevodina T.G. Primenenie prokurorom psihologicheskih znanij pri podderzhanii v sude gosudarstvennogo obvineniya po ugolovnym delam s uchastiem nesovershennoletnih [The Use of Psychological Knowledge by the Prosecutor in Maintaining the State Prosecution in Court in Criminal Cases Involving minors]. Zakony Rossii: opyt, analiz, praktika [Laws of Russia: Experience, Analysis, Practice], 2016, no. 8, pp. 76-79.
2. Gulyagin A.Yu., Bozoyan A.O. Nesovershenstvo pravovogo regulirovaniya statusa prokurora kak koordinatora i sub'ekta profilaktiki pravonarushenij [Imperfection of Legal Regulation of the Status of the Prosecutor as a Coordinator and Subject of Crime Prevention]. Rossijskaya yusticiya [Russian Justice], 2017, no. 8, pp. 55-58.

3. Kostenko E.N. Ob'ekty prokurorskogo nadzora za ispolneniem zakonov o profilaktike beznadzornosti i pravonarushenij nesovershennoletnih [Objects of Prosecutor's Supervision Over the Implementation of Laws on the Prevention of Neglect and Juvenile Delinquency]. Sovremennoe pravo [Modern Law], 2018, no. 7-8, pp. 28-33.

4. Kostenko E.N. Pravovoe regulirovanie prokurorskogo nadzora za ispolneniem zakonov o profilaktike beznadzornosti i pravonarushenij nesovershennoletnih [Legal Regulation of Prosecutorial Supervision Over the Implementation of Laws on the Prevention of Neglect and Juvenile Delinquency]. Aktual'nye problemy rossijskogo prava [Actual Problems of Russian Law], 2018, no. 9, pp. 226-231.

5. Sadovnikova M.N. Vostrebovannost' mediativnyh tekhnologij $\mathrm{v}$ sisteme profilaktiki prestupnosti nesovershennoletnih [Demand for Media Technologies in the System of Prevention of Juvenile Delinquency]. Sibirskij yuridicheskij vestnik [Siberian Legal Bulletin], 2013, no. 2, pp. 82-85.

6. Sachkov V.P. Sovershenstvovanie sposobov zashchity prokurorom prav i zakonnyh interesov nesovershennoletnih [Improving the Ways of Protecting the Rights and Legitimate Interests of Minors by the Prosecutor]. Molodoj uchenyj [Young Scientist], 2018, no. 19, pp. 319-321.

7. Shamrin M.Yu. Vzaimodejstvie Upolnomochennogo po pravam rebenka s organami prokuratury Rossii: teoretiko-pravovoj aspekt [Interaction of the Commissioner for the Rights of the Child with the Prosecutor's Office of Russia: Theoretical and Legal Aspect]. Administrativnoe pravo $i$ process [Administrative Law and Process], 2016, no. 12 , pp. 60-68.

8. Shinkaruk V.M., Fantrov P.P. Koordinaciya deyatel'nosti pravoohranitel'nyh organov i konstruktivnyh associacij grazhdan v kontekste profilaktiki molodezhnogo ekstremizma [Coordination of the Activities of Law Enforcement Agencies and Constructive Associations of Citizens in the Context of the Prevention of Youth Extremism]. Voprosy rossijskogo i mezhdunarodnogo prava [Questions of Russian and International Law], 2020, no. 7A, pp. 111-120.

9. Shinkaruk V.M., Fantrov P.P., Solovyova N.A. Protivodejstvie ekstremizmu v molodezhnoj srede: rol' prokurorskogo nadzora za ispolneniem zakonodatel'stva $\mathrm{v}$ dannoj sfere [Counteracting 
Extremism Among the Youth: The Role of Prosecutorial Supervision Over the Implementation of Legislation in this Area]. Vestnik Volgogradskoj akademii MVD
Rossii [Bulletin of the Volgograd Academy of the Ministry of Internal Affairs of Russia], 2020, no. 4, pp. 178-188.

\section{Information About the Authors}

Pavel P. Fantrov, Candidate of Sciences (Politics), Associate Professor, Department of Criminal Procedure and Criminalistics, Volgograd State University, Prosp. Universitetsky, 100, 400062 Volgograd, Russian Federation, pavelfantrov@volsu.ru, https://orcid.org/0000-0002-9832-6169

Mikhail V. Bobovkin, Doctor of Sciences (Jurisprudence), Professor, Department of Criminal Law, Criminal Procedure and Criminalistics, Russian University of Transport, Obraztsova St, 9, Bld. 9, 127994, GSP-4 Moscow, Russian Federation; Professor, Department of Digital Criminalistics, Bauman Moscow State Technical University, $2^{\text {nd }}$ Baumanskaya St, 5, Bld. 1, 105005 Moscow, Russian Federation; Professor, Department of Document Research of the Educational and Scientific Complex of Forensic Examination, Moscow University of the Ministry of Internal Affairs of Russia named after V.Ya. Kikot, Akademika Volgina St, 12, 117997 Moscow, Russian Federation, mbobovkin@yandex.ru, https://orcid.org/0000-0001-6264-0335

Stanislav A. Medentsov, Assistant Prosecutor, Prosecutor's Office of Tsentralny District of Volgograd, Prosp. Lenina, 29A, 400131 Volgograd, Russian Federation, medentzov@inbox.ru, https://orcid.org/0000-0002-8049-9344

\section{Информация об авторах}

Павел Петрович Фантров, кандидат политических наук, доцент кафедры уголовного процесса и криминалистики, Волгоградский государственный университет, просп. Университетский, 100, 400062 г. Волгоград, Российская Федерация, pavelfantrov@volsu.ru, https://orcid.org/0000-0002-9832-6169

Михаил Викторович Бобовкин, доктор юридических наук, профессор, профессор кафедры уголовного права, уголовного процесса и криминалистики, Российский университет транспорта, ул. Образцова, 9, стр. 9, 127994, ГСП-4 г. Москва, Российская Федерация; профессор кафедры цифровой криминалистики, Московский государственный технический университет им. Н.Э. Баумана, 2-я Бауманская ул., 5, стр. 1, 105005 г. Москва, Российская Федерация; профессор кафедры исследования документов учебно-научного комплекса судебной экспертизы, Московский университет МВД России им. В.Я. Кикотя, ул. Академика Волгина, 12, 117997 г. Москва, Российская Федерация, mbobovkin@yandex.ru, https://orcid.org/0000-0001-6264-0335

Станислав Андреевич Меденцов, помощник прокурора, Прокуратура Центрального района г. Волгограда, просп. Ленина, 29A, 400131 г. Волгоград, Российская Федерация, medentzov@inbox.ru, https://orcid.org/0000-0002-8049-9344 